\section{Long-Read Genome Sequence Resources of Xanthomonas citri pv. punicae Strain Bagalkot Causing Pomegranate Bacterial Blight}

\author{
Dattatraya Hegde Radhika, ${ }^{1}$ Raghavendra Gunnaiah, ${ }^{1, \dagger}$ Ashwini Lamani, ${ }^{1}$ Dadapeer \\ Peerjade, ${ }^{2}$ and Rudrappa Chandrashekhar Jagadeesha ${ }^{1}$ \\ ${ }^{1}$ Department of Biotechnology and Crop Improvement, College of Horticulture, Bagalkot, University \\ of Horticultural Sciences, Bagalkot, India \\ ${ }^{2}$ Directorate of Research, University of Horticultural Sciences, Bagalkot, India
}

Funding

This project was funded by Department of Science and Technology, Science and Engineering Research Board, Government of India (project number ECR/2017/000914).

\begin{abstract}
Xanthomonas citri pv. punicae causing bacterial blight is a devastating disease of pomegranate in India and Pakistan. Most xanthomonads use the type III secretion system to inject transcription activator-like effector (TALE) proteins into the host cell. TALEs bind to the effector-binding elements in the promoter of host susceptibility genes, triggering disease development. PacBio single-molecule real-time long-read sequencing technology was used to identify the TALE-encoding genes, which is otherwise not possible using next-generation short-read sequencers. In all, $1.74 \mathrm{~Gb}$ of raw data containing 368,980 subreads, with an average read length of $4,724 \mathrm{bp}$ and longest read length of 77,471 , were generated. Subreads were assembled into 15 scaffolds generating approximately $5.4 \mathrm{Mb}(348 \times)$ of genome. $X$. citri pv. punicae exhibited close lineage with $X$. citri pv. citri with $98.78 \%$ average nucleotide identity. Of the 4,263 protein-coding genes, 11 nonTALE type III effectors and 2 TALE-encoding genes were identified.
\end{abstract}

Bacterial blight, caused by the Gram-negative bacterium Xanthomonas citri pv. punicae (Constantin et al. 2016; Hingorani and Singh 1960), previously referred to as $X$. axonopodis pv. punicae (Hingorani and Singh 1960; Vauterin et al. 1995), is a major constraint in pomegranate cultivation, leading to 60 to $80 \%$ yield loss (Ramesh and Ram 1991; Sharma et al. 2017). Bacterial blight affects the aboveground plant parts, including leaf, fruit, and stem. Early water-soaked lesions to late necrotic blighting symptoms are initially observed on the leaves. Isolated water-soaked lesions on the fruit coalesce to form Y-, X-, and L-shaped cracks and split fruit. Under severe and prolonged disease conditions, canker and breakage of the stem can lead to deterioration of an entire orchard (Sharma et al. 2017). Although the disease was first reported in India, its prevalence has been reported in Pakistan (Akhtar and Bhatti 1992), South Africa (Petersen et al. 2010), and Turkey (Icoz et al. 2014). Host resistance breeding is believed to be the best bacterial blight management practice in pomegranate; however, no resistance sources are reported to date. Identification of pathogenicity factors and characterization of the host response mechanism is crucial for developing host resistance in elite cultivars.

Many Xanthomonas spp. secrete transcription activator-like effector (TALE) proteins through the type III secretion system (Bogdanove et al. 2010; White et al. 2009). TALEs bind to the specific TALE-binding elements in the promoter region of host genes and trigger the expression of multiple disease susceptibility genes (Zhang et al. 2015). The DNA-binding

${ }^{\dagger}$ Corresponding author: R. Gunnaiah; raghavendra.gunnaiah@uhsbagalkot.edu.in

The author(s) declare no conflict of interest.

Accepted for publication 10 March 2021. 
Table 1. PacBio sequencing, assembly, and annotation statistics of Xanthomonas citri pv. punicae genome

\begin{tabular}{lc} 
Attributes $^{a}$ & Value \\
Raw subreads & 368,980 \\
Raw bases & $1,743,387,061$ \\
Raw longest subread length (bp) & 77,471 \\
Raw subread $N_{50}(\mathrm{bp})$ & 5,961 \\
Total assembly (bp) & $5,436,898$ \\
GC (\%) & 63.94 \\
Assembly N ${ }_{50}(\mathrm{bp})$ & $5,158,969$ \\
Longest scaffold (bp) & $5,158,969$ \\
Total BUSCO groups searched in & 221 \\
Complete BUSCOs & 216 \\
Complete and single-copy BUSCOs & 205 \\
Complete and duplicated BUSCOs & 11 \\
Fragmented BUSCOs & 1 \\
Missing BUSCOs & 4 \\
Predicted genes & 4,757 \\
Coding genes & 4,652 \\
Protein coding genes & 4,263 \\
Total RNA-coding genes & 105 \\
Pseudo-genes & 389 \\
Type III secretion system effectors & 11 \\
TALEs & 2 \\
Pseudo-TALEs & 4 \\
\hline a BUSCOs = benchmarking universal single-copy orthologous groups and TALEs = transcription \\
activator-like effectors. &
\end{tabular}

specificity of TALEs is determined by a central domain of near-perfect 33- to 35-amino-acid repeats with two variable amino acids at positions 12 and 13, termed as repeat-variable di-residues (Xu et al. 2017). Genes encoding TALEs occur in multiple copies and contain multiple simple, near-perfect repeats within each gene, which makes it challenging to accurately assemble the repeats through short-read sequencing technologies (Sharma et al. 2012). Long-read sequencing of $X$. citri pv. punicae strain Bagalkot isolated from Bagalkot, a major pomegranate-growing area in Karnataka, India, was carried out, and genes encoding non-TALE type III effectors and TALEs were identified by PacBio single-molecule real-time (SMRT) sequencing.

$X$. citri pv. punicae was isolated from bacterial-blight-infected pomegranate leaves and cultured on nutrient glucose (NG) agar ( $\mathrm{pH} 7 \pm 0.2$ ) media at $28 \pm 2^{\circ} \mathrm{C}$ for 2 days. Pathogenicity of the isolated culture was reconfirmed by challenge inoculation on the blight-susceptible pomegranate plants. DNA was isolated from the $X$. citri pv. punicae cultured on NG broth. Identity of the $X$. citri pv. punicae with other isolates of $X$. citri pv. punicae was confirmed by sequencing a partial $16 \mathrm{~S}$ ribosomal RNA (rRNA) gene and sequence similarity analysis. $X$. citri pv. punicae 16S rRNA gene MN971672.1 exhibited 100\% identity with the 16S rRNA gene of most of the reported $X$. citri pv. punicae isolates from India (Kumar et al. 2020). For SMRT sequencing, high-quality $X$. citri pv. punicae DNA was fragmented by exonuclease treatment and an average insert size of 8,455 bp was processed with the SMRTbell template prep kit v1.0 (Pacific Biosciences, India) using the manufacturer's protocol and sequenced on a PacBio Sequel at AgriGenome Labs Pvt. Ltd., Kochi, India. Raw polymerase reads were partitioned into 368,980 subreads with longest, mean, and $\mathrm{N}_{50}$ subread lengths of $77,471,4,724$, and $5,961 \mathrm{bp}$, respectively, constituting $348 \times$ genome coverage (Table 1). Long subreads were assembled into 15 contigs with Flye (v.2.5) assembler (Mikheenko and Kolmogorov 2019). MUMmer algorithm-based average nucleotide identity (ANIm) of the newly assembled $X$. citri pv. punicae genome with 36 representative genomes of Xanthomonas spp. (downloaded from NCBI) was calculated using JSpecies v. 1.2.1. (Richter and Rosselló-Móra 2009). The completeness of the final assembly was evaluated by benchmarking universal single-copy orthologous (BUSCO v.4.1.4) software (Simão et al. 2015). NCBI Prokaryotic Genome Annotation Pipeline (PGAP) version 4.9 was used for functional annotation of genes. AnnoTALE 1.4.1 was used to detect and annotate TALE genes (Grau et al. 2016).

The $X$. citri pv. punicae genome was assembled into a total genome length of approximately $5.4 \mathrm{Mb}$ with a total $\mathrm{G}+\mathrm{C}$ content of $63.94 \%$ (Table 1). The $\mathrm{N}_{50}$ and $\mathrm{L}_{50}$ contig lengths 
were 5,158,969 and $1 \mathrm{bp}$, respectively. The longest contig $8(5,158,969 \mathrm{bp})$ exhibited 99.96 and $99.98 \%$ identity with the short-read assembled reference genome LMG859 (NZ_CAGJ00000000.1) and hybrid assembly (Illumina Miseq and Nanopore) (CP030163.1). Contig 9 (Plasmid pUnnamed1, 28823 bp) and contig 11 (Plasmid pUnnamed2, 48249 bp) were identical to the plasmids of previously sequenced $X$. citri pv. punicae, with 98.33 and 99.12\% identity to CP030179.1 and CP030170.1, respectively. Contig 8 also exhibited close lineage with the Xanthomonas representative genome $X$. citri pv. citri $(98.78 \%$ ANIm; NZ_CP009016.1) which causes citrus canker disease in citrus. Of the 4,757 genes predicted, 4,652 are coding sequences (4,263 proteins, and 389 pseudogenes) and 105 are RNA genes (three each of 5S RNA, 16S RNA, and 23S RNA; 61 transfer RNAs; and 35 noncoding RNA) (Table 1). Fewer pseudogenes were detected in the PacBio sequenced assembly compared with the other assemblies available in the NCBI database. Of the 1,152 BUSCO groups (BUSCOs) searched, PacBio assembly displayed 1,139 complete BUSCOs (approximately $98.9 \%$ ) without any duplicates, six fragmented BUSCOs, and seven missing BUSCOs, exemplifying the accuracy of bacterial genome sequencing and assembly. Eleven nonTALE type III effector proteins and one type VI secretion system were identified through automated genome annotation using PGAP. Furthermore, two novel TALE effectors belonging to the class I and class II TALE families and four pseudo-TALEs were identified for the first time in the $X$. citri pv. punicae genome using AnnoTALE. Interestingly, two pseudoTALEs were identified in Plasmid pUnnamed2. Short-read assembly of $X$. citri pv. punicae (NZ_CAGJ00000000.1) didn't return any TALEs, and only three TALEs were discovered in the hybrid assembly of $X$. citri pv. punicae (CP030163.1). Newly discovered TALE1 and TALE2 were 96.66 and $94.48 \%$ identical, respectively, to the $X$. oryzae pv. oryzae strain race 4 TALE 7 (MN128606), with $>99 \%$ coverage. $X$. citri pv. punicae TALEs need to be validated and their binding proteins in host target genes need to be identified before starting a resistance breeding program.

The power of long-read PacBio sequencing technology was used to obtain a genome assembly of $X$. citri pv. punicae of high depth (348x) and high consensus accuracy that allowed the capture of repetitive regions such as TALEs. Identification of genes encoding type III secretion system effector proteins and TALEs is a first step toward the identification of the corresponding susceptibility genes. With the high-quality pomegranate genome available (MABG00000000.2), TALE-binding DNA elements will be identified and deployed in resistance breeding.

\section{Data Availability}

Complete genome assembly and gene annotation data have been deposited at GenBank under the accession number NZ_JAAQOY000000000.1 (BioProject: PRJNA612770).

\section{Acknowledgments}

We thank Karnataka Biotechnology and Information Technology Services, Government of Karnataka, India for funding to build laboratory and infrastructure facility.

\section{Literature Cited}

Akhtar, M., and Bhatti, M. R. 1992. Occurrence of bacterial leaf spot of pomegranate in Pakistan. Pak. J. Agric. Res. 13:95-97.

Bogdanove, A. J., Schornack, S., and Lahaye, T. 2010. TAL effectors: Finding plant genes for disease and defense. Curr. Opin. Plant Biol. 13:394-401.

Constantin, E., Cleenwerck, I., Maes, M., Baeyen, S., Van Malderghem, C., De Vos, P., and Cottyn, B. 2016. Genetic characterization of strains named as Xanthomonas axonopodis pv. dieffenbachiae leads to a taxonomic revision of the $X$. axonopodis species complex. Plant Pathol. 65:792-806

Grau, J., Reschke, M., Erkes, A., Streubel, J., Morgan, R. D., Wilson, G. G., Koebnik, R., and Boch, J. 2016. AnnoTALE: Bioinformatics tools for identification, annotation, and nomenclature of TALEs from Xanthomonas genomic sequences. Sci. Rep. 6:21077.

Hingorani, M. K., and Singh, N. J. 1960. Xanthomonas punicae sp. nov. on Púnica granatum L. Indian J. Agric. Sci. 29:45-48.
Icoz, S. M., Polat, I., Sulu, G., Yilmaz, M., Unlu, A., Soylu, S., Bozkurt, I. A., and Baysal, Ö. 2014. First report of bacterial blight of pomegranate caused by Xanthomonas axonopodis pv. punicae in Turkey. Plant Dis. 98:1427.

Kumar, A., Sharma, J., Munjal, V., Sakthivel, K., Thalor, S., Mondal, K., Chinchure, S., and Gharate, R. 2020. Polyphasic phenotypic and genetic analysis reveals clonal nature of Xanthomonas axonopodis pv. punicae causing pomegranate bacterial blight. Plant Pathol. 69:347-359.

Mikheenko, A., and Kolmogorov, M. 2019. Assembly Graph Browser: Interactive visualization of assembly graphs. Bioinformatics 35:3476-3478.

Petersen, Y., Mansvelt, E., Venter, E., and Langenhoven, W. 2010. Detection of Xanthomonas axonopodis pv. punicae causing bacterial blight on pomegranate in South Africa. Australas. Plant Pathol. 39:544-546.

Ramesh, C., and Ram, K. 1991. Studies on bacterial blight (Xanthomonas campestris pv. punicae) of pomegranate. Indian Phytopathol. 44:370-372.

Richter, M., and Rosselló-Móra, R. 2009. Shifting the genomic gold standard for the prokaryotic species definition. Proc. Natl. Acad. Sci. U.S.A. 106:19126-19131.

$\mathbf{8 7 6}$ / Molecular Plant-Microbe Interactions 
Sharma, J., Sharma, K., Kumar, A., Mondal, K., Thalor, S., Maity, A., Gharate, R., Chinchure, S., and Jadhav, V. 2017. Pomegranate bacterial blight: Symptomatology and rapid inoculation technique for Xanthomonas axonopodis pv. punicae. J. Plant Pathol. 99:109-119.

Sharma, V., Midha, S., Ranjan, M., Pinnaka, A. K., and Patil, P. B. 2012. Genome sequence of Xanthomonas axonopodis pv. punicae strain LMG 859. J. Bacteriol. 194:2395.

Simão, F. A., Waterhouse, R. M., loannidis, P., Kriventseva, E. V., and Zdobnov, E. M. 2015. BUSCO: Assessing genome assembly and annotation completeness with single-copy orthologs. Bioinformatics 31:3210-3212.
Vauterin, L., Hoste, B., Kersters, K., and Swings, J. 1995. Reclassification of Xanthomonas. Int. J. Syst. Evol. Microbiol. 45:472-489.

White, F. F., Potnis, N., Jones, J. B., and Koebnik, R. 2009. The type III effectors of Xanthomonas. Mol. Plant Pathol. 10:749-766.

Xu, Z.-y., Zou, L.-f., Cai, L.-I., Yang, Y.-y., and Cheng, G.-y. 2017. Action modes of transcription activator-like effectors (TALEs) of Xanthomonas in plants. J. Integr. Agric. 16:2736-2745.

Zhang, J., Yin, Z., and White, F. 2015. TAL effectors and the executor R genes. Front. Plant Sci. 6:641. 